\title{
Towards an understanding of the virtual context in mobile learning
}

\author{
Sarah Cornelius $^{\mathrm{a} *}$ and Phil Marston ${ }^{\mathrm{b}}$ \\ ${ }^{a}$ School of Education, University of Aberdeen, UK; ${ }^{b}$ Centre for Learning and Teaching, \\ University of Aberdeen, UK
}

(Received 14 January 2009; final version received 2 July 2009)

\begin{abstract}
Much of the literature theorising mobile learning emphasises the importance of context with physical and social contexts identified to date. Our work to design and implement authentic mobile simulation activities using SMS text messaging suggests that a third context may also be important. This is a virtual context, the learner-created cognitive space within which the activity takes place. The arrival of a message during a simulation activity will disrupt the real world physical and social contexts in which the learner finds themselves and transfer them into the virtual context. We argue that this disruptive power of the mobile device to shift the user's presence may be one of the distinguishing characteristics of certain mobile learning applications. This paper will explore the idea of the virtual context and discuss the role of issues of context, presence and disruption, illustrating these with reference to a case study of mobile simulation learning using SMS text messaging.
\end{abstract}

Keywords: mobile learning; SMS; simulation; virtual context; presence

\section{Introduction}

The landscape of mobile learning is still being sculpted as innovative applications emerge. The use of mobile phones is now almost ubiquitous amongst students in many parts of the world (in the UK as many as $99 \%$ of undergraduates already have one Margaryan et al. 2008) and one of the main uses to which they put their phones is SMS (Short Messaging Service or text messaging). SMS provides "anywhere, anytime" (Geddes 2004, 1) access to learners and a channel for communication with which they are generally familiar and comfortable. SMS-related applications have to date covered a number of areas: such as providing administrative information (e.g. DuVall et al. 2007), offering revision and test materials in the form of short quizzes (e.g. Ogino et al. 2008), facilitating language learning (e.g. Kukulska-Hulme and Shield 2008; Cavus and Ibrahim 2009), and improving feedback and interaction in lecture-related applications (e.g. Kinsella 2009; Wang et al. 2009).

This paper focuses on simulation activities using SMS text messaging. Simulations have a wider history in mobile learning, not always employing SMS. One category of simulations is the participatory simulation (Colella 2000), in which learners "act out key parts in an immersive recreation of a dynamic system" (Naismith et al. 2004, 13) and their actions have an effect on progress of the simulation. Examples implemented

*Corresponding author. Email: s.cornelius@abdn.ac.uk 
with mobile technologies include simulations representing the spread of a virus (Colella 2000) and a game to encourage the development of a conceptual understanding of animal behaviour (Facer et al. 2004). In the augmented reality simulation Environmental detectives (Squire and Klopfer 2007) learners play the role of environmental scientists conducting investigations into a simulated chemical spill. The area of simulation of particular interest to our work is that of authentic real-time decision-making scenarios - situations in which the use of a mobile device is authentic and appropriate. In these situations (e.g. disaster management, mentoring, medical emergency) a decision maker is 'on the move' so mobile phone contact would be appropriate. Rapid decision making is required, with decisions, which will affect the progress and outcome of the situation, communicated by mobile phone. Indeed SMS text messaging has become important in real-world emergency situations (e.g. BBC 2008), and despite potential difficulties such as the problem of guaranteeing message arrival (Latimer 2008) it is likely that it will remain an important tool for decision makers.

Simulations have particular relevance for the development of work-related skills, and have been applied in non-mobile learning, such as for the development of practical skills in geo-spatial data handling using a 'Virtual Placement' in the geosciences (Cornelius, Medyckyj-Scott, et al. 2008). The Virtual Placement, which supports learners playing the role of a research assistant undertaking an assessment of the visibility of wind farms for a consultancy company, also incorporates a real-time element, and email is used to provide a channel of communication between members of a virtual team and the student. In mobile learning this type of simulation is less well represented to date and difficult to place easily into classifications of applications such as those developed by Naismith et al. (2004), Patten, Arnedillo Sánchez, and Tangney (2006) or Frohberg, Göth, and Schwabe (2009).

Winters (2006) briefly reviews the conceptual development of mobile learning. He considers that early work to develop definitions of mobile learning focused on the technology, then, the mobility of the learner came to the fore. More recently mobile learning has been considered as communication in context building on reinterpretations of activity theory (Sharples 2005) and Laurillard's conversational framework (Laurillard 2002). In line with this trend, although drawing on activity theory alone, Wali, Winters, and Oliver $(2008,55)$ offer a definition of mobile learning as "learning that occurs as a result of pursuing learning activities that are directed towards achieving the same objective across multiple contexts (both social and physical)". Frohberg, Göth, and Schwabe (2009) also draw on activity theory to evaluate and categorise mobile learning projects, identifying six factors (context, tools, control, communication, subject, and object) that can be used to describe mobile learning projects. They consider the most significant of these factors to be context, but restrict their interpretation of context to "where the learning takes place" (7). Context has also been a concern of other researchers including Yang (2006), Kurti, Spikol, and Milrad (2008) and Hansen and Bouvin (2009). The focus of these studies has been context awareness, which allows mobile devices to respond automatically based on users' location.

In this paper we revisit the idea of multiple contexts, adding to the contexts suggested by Wali, Winters, and Oliver (2008), Kurti, Spikol, and Milrad (2008), Hansen and Bouvin (2009) and Frohberg, Göth, and Schwabe (2009) a 'virtual context' that aids conceptualisation of mobile simulation activities. A case study which illustrates the role of the virtual context in simulation activities is provided and the concept discussed in the light of other perspectives on presence and disruption in mobile communication. 


\section{Towards the virtual context}

The notion of context is important in recent conceptualisations of mobile learning. Sharples, Taylor, and Vavoula $(2005,5)$ describe context as "a dynamic entity, constructed by the interactions between learners and their environment" and Wali, Winters, and Oliver (2008) highlight the role of multiple contexts in mobile learning, identifying two particular contexts - the physical (the 'environment' which surrounds the user) and social (that which arises from constructive interaction between people and technology). Wali, Winters, and Oliver argue for the application of Engeström's activity theory framework to mobile learning in which the social context is considered through rules, community and division of labour. This is at odds with Sharples, Taylor, and Vavoula's (2007) suggestion for the distinction between two layers representing technological and semiotic components of the system. It may be the case that mobile phones and SMS messaging are "tools [that] when used, become an extension of the body" (Gibson 1979 cited by Rettie 2005, 25), so for student users a separate technological layer is no longer necessary. In line with Wali, Winters, and Oliver (2008) and Frohberg, Göth, and Schwabe (2009), we would argue that a simplified version of the activity system allows effective analysis of mobile learning activities.

Frohberg, Göth, and Schwabe $(2009,7)$ consider four types of context: independent, formalised, physical and socialising. They suggest context is independent when "the current environment of the learner has no relationship to their current issue of learning". This context is considered of low pedagogic ambition and low complexity. However, this low ranking does not allow for the use of an independent context as part of a pedagogic design, for example to represent an authentic virtual context for learners participating in a mobile simulation activity. When a simulated event occurs the student has no control over the time or place in which they have to address the problem and thus the physical location of the student is, by design, not relevant to the learning activity, but the fact that the location is not relevant is important.

Further up Frohberg, Göth, and Schwabe's (2009) scale of complexity and pedagogic ambition is their notion of physical context. Here, "the place of being is relevant for the learning issue" (8). In a mobile simulation there is a place that is relevant to the activity, but it is a fictional or virtual representation of a (possibly real) place. Actual physical presence in that place is not necessary to engage with the activity. Participants are 'transported' to the virtual place by their imagination and the experience of 'presence' (Rettie 2005). This is quite different to Frohberg, Göth, and Schwabe's (2009) notion of physical context that (in common with much of the literature on mobile learning) requires interaction with a physical space, such as a museum, gallery or field location.

Thus, in addition to the four contexts suggested by Frohberg, Göth, and Schwabe (2009) there seems to be a need for an additional context in this framework where significant and sophisticated learning activities take place and where the physical location of the learner is not relevant.

Wali, Winters, and Oliver $(2008,56)$ define context as "a combination of the properties of the physical location where the learning activity takes place and the rules and division of labour within the community that the learner belongs to" and argue that it is context crossing - changes in both the physical and social contexts - that distinguishes mobile learning from static learning. Context crossing is certainly associated with mobile simulation activities. In such an activity the physical context is that which surrounds the user at the time when they receive a message. This may be a classroom, 
workplace, home or any other location, which will have an associated social context. As time progresses the learner will move (or cross) to a different physical and social context, where the next message will be received.

However, the Wali, Winters, and Oliver (2008) model does not allow for representation of the context of the simulation scenario itself which could be a different geographical location in which an event is unfolding. They do, however, suggest that mobile learning may help to create contexts that cannot be created with conventional learning devices, as it certainly does in the simulation case. Thus an additional context, which we have termed the 'virtual context', can be identified. This context is intimately associated with the learning activity and it is returned to (crossed to) by the learner each time they engage with the activity. The virtual context has physical properties (physical features and perhaps a geography of its own - real or conceptual - so that it can be regarded as a place or a space) and the learner belongs to an associated virtual community (the community associated with their role in the scenario) with rules and a division of labour. Key to this notion of virtual context is the concept of place as described by Rettie (2005). She describes the potential for new forms of communication such as mobile phones to "change perceptions of time and place" and the disruptive nature of mobile phones can be expressed as "the experience of presence between parallel interactions, creating absent presence in the face-to-face interaction, as presence is diverted to the phone interaction" (Rettie 2005, 16-7).

As an illustration, imagine, for example, a simulation activity where the student is required to take the role of a decision maker managing the emergency services in response to a volcanic eruption on in the island of Sicily. The student may be located at their normal place of study, home, place of work or in a social space - these are possible physical contexts which all have their own associated social contexts (rules and division of labour). However the simulation activity requires the student to also consider the physical location of the volcano (Sicily) and this becomes the virtual context. The cultural and organisational characteristics of Sicily provide the social context (rules and division of labour) to accompany this virtual context. In order to complete the simulation activity, the student will cross physical contexts and also cross into and out of the virtual context. Regardless of their physical context, during their engagement with the simulation their attention will be on the virtual context (Sicily).

The framework for analysing mobile learning provided by Wali, Winters, and Oliver (2008) has been adapted to include this idea of the virtual context (Figure 1)

The development of a virtual context for mobile simulation activities has some significant advantages: it remains persistent throughout the learning activity; it requires cognitive engagement and may enhance the authenticity of a scenario; and it provides a disruptive element to learning.

Once established, the virtual context remains persistent for the duration of a mobile activity. Whilst the physical context within which the learner finds themselves may change (work, home, university, etc.), the virtual context endures. For the duration of a simulation activity the learner 'takes with them' the virtual context. It will have its own rules for social interaction - for example responses may be required in a particular format and/or within a particular timeframe. Thus during a mobile simulation activity familiarity and comfort with the virtual context can be developed and maintained to encourage engagement with the activity.

A virtual context can be based on a real physical environment, or be a completely imaginary space. A certain degree of cognitive investment is required by the student 


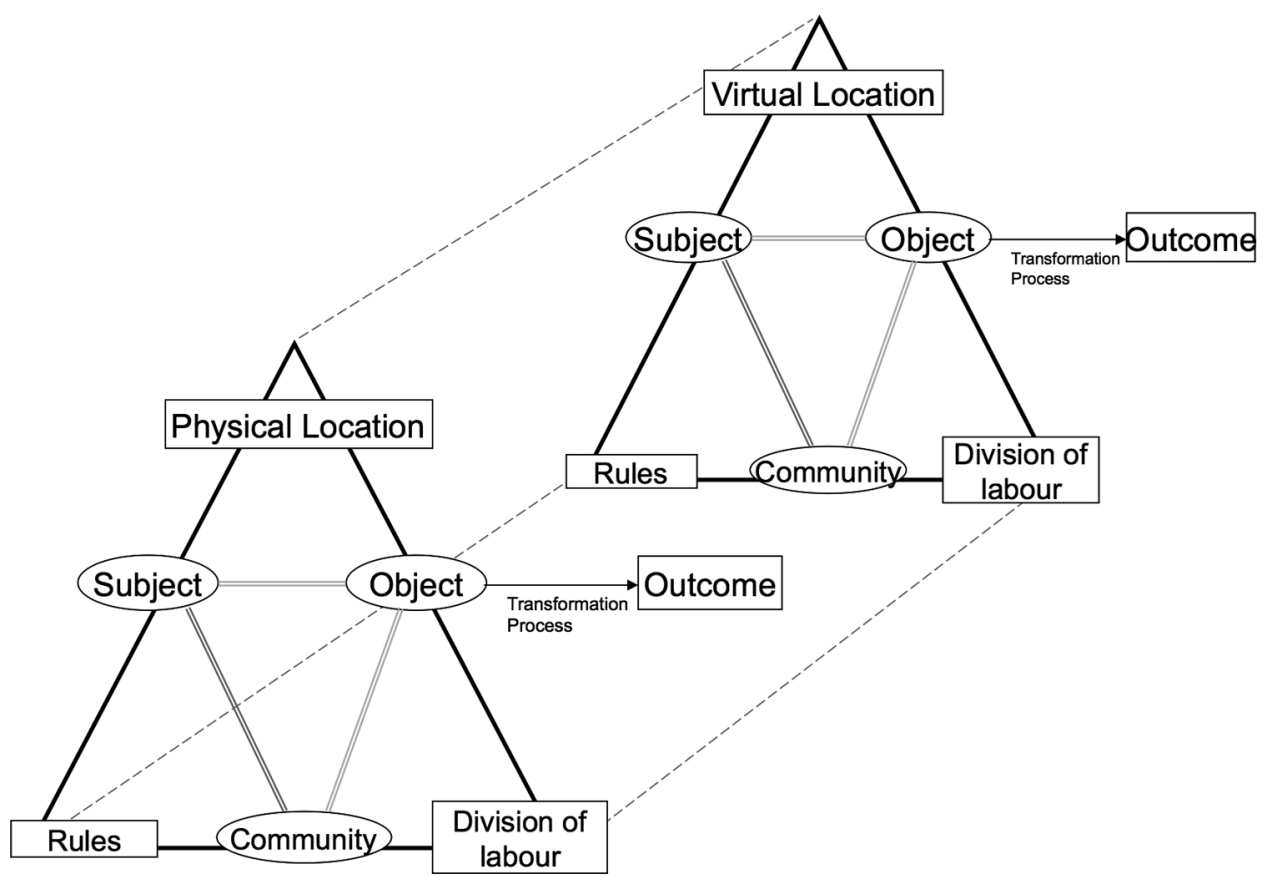

Figure 1. The physical and virtual contexts (adapted from Wali, Winters, and Oliver 2008).

to help them 'imagine' all the characteristics of the virtual context. The features of the simulation environment will be created within the student's imagination and the impact of their decisions will have to be visualised. The experience is similar to that required to imagine a world from reading a book rather than the more structured and 'helpful' approach of a virtual world or real life role play. Baños et al. (2005) found that using imagination to construct a sense of place could provide a greater sense of reality than using virtual reality. The use of a mode of communication (such as SMS) that is indistinguishable from that which would be used in a real world situation enhances this experience of place. Placing the student in a first person role increases their immersion, making them feel part of the activity rather than a witness to an avatar. This additional cognitive engagement may be beneficial for the learner, requiring deeper thinking and involvement.

One of the features which this virtual context carries with it is the ability to disrupt. When a learner receives a message from a simulation, it disrupts their current physical and social contexts. It will transport them, albeit temporarily, to the virtual context. The opportunity for disruption is enhanced when simulations are carried out in real time, with messages arriving at possibly unexpected or inconvenient times. This disruption and repeated return to the virtual context offers opportunities for microlearning and at the same time retains engagement with the task over an extended period of time.

It is this ability to impinge on the learner's current context which appears to be one of the defining characteristics of mobile simulations. For example, a hard copy book also provides the advantages of retaining a virtual context and a requirement for cognitive engagement. It also allows the reader to return to the virtual context repeatedly. Indeed there are books - a well known example is The Warlock of Firetop 
Mountain (Jackson and Livingston 1982) - which require decision making in line with the model used for simulation activities. However, a book will be read at the reader's convenience, rather than at a time dictated by the simulation and the book will not disrupt the reader's other activities. Other engaging technologies from a games background which offer a similar level of disruption include the Tamagotchi ${ }^{\circledR}$, which pesters the 'owner' to keep it alive and well.

\section{A real-time authentic decision-making scenario}

A flood disaster simulation is outlined below as a case study of a real-time authentic decision-making scenario which has been tested and evaluated. Full details of the design and evaluation of a pilot version of this simulation are reported in Gemmell, Finlayson, and Marston (in press). Following the success of this pilot, twenty three final year undergraduates studying Applied Geomorphology participated in the simulation in 2008. A mixed methods study, involving learners, tutors and technologists, was undertaken to gain a holistic view of the activity and investigate learners' experiences. The study, informed by an activity theory perspective, aimed to uncover issues related to control, context and communication. Preliminary results were reported in Cornelius, Gemmell, and Marston (2008). Seventy percent of the cohort responded to a detailed questionnaire after the simulation was completed, and two students, the tutor and educational technologist were interviewed. Participation throughout was voluntary and it was disappointing that additional students could not be recruited for interviews. Comments from the two volunteers may be unrepresentative of the group as a whole, however, they are considered valuable in providing an insight into the experiences of learners who had a positive experience of the simulation. The scenario is outlined first below, and findings from the evaluation are then discussed in the light of issues raised by the virtual context.

\section{The flood disaster simulation}

During the flood disaster simulation learners were asked to imagine that they were the manager of civil defence utilties in a French town. The town was given a fictional name for the simulation, but the scenario was based on a real event which took place in a real location. A local manager would have some understanding of the geographical location, and learners were provided with background information on the area in advance of the simulation. As the simulation began, local weather conditions were changing and the manager had to respond to changes to prevent a flood disaster. Their mobile phone was their most important channel of communication and as the situation unfolded they received updates about the situation and communicated decisions on what action they wished to take by SMS text message (Figure 2). The simulation ran in real time over a 72-hour period and the use of mobile phones allowed the 'manager' to be contacted anywhere and make quick decisions to help control the situation.

The simulation provided a personalised experience for each learner as the decision they made at each 'event horizon' determined their pathway through a decision tree to an appropriate scenario end point. Decisions had to be made within a two hour period of receiving information, and if this deadline was missed the system implemented a decision on behalf of the student. This reflects the real life situation where, even if the manager were unavailable, a decision would have to be made in such a rapidly developing scenario. 


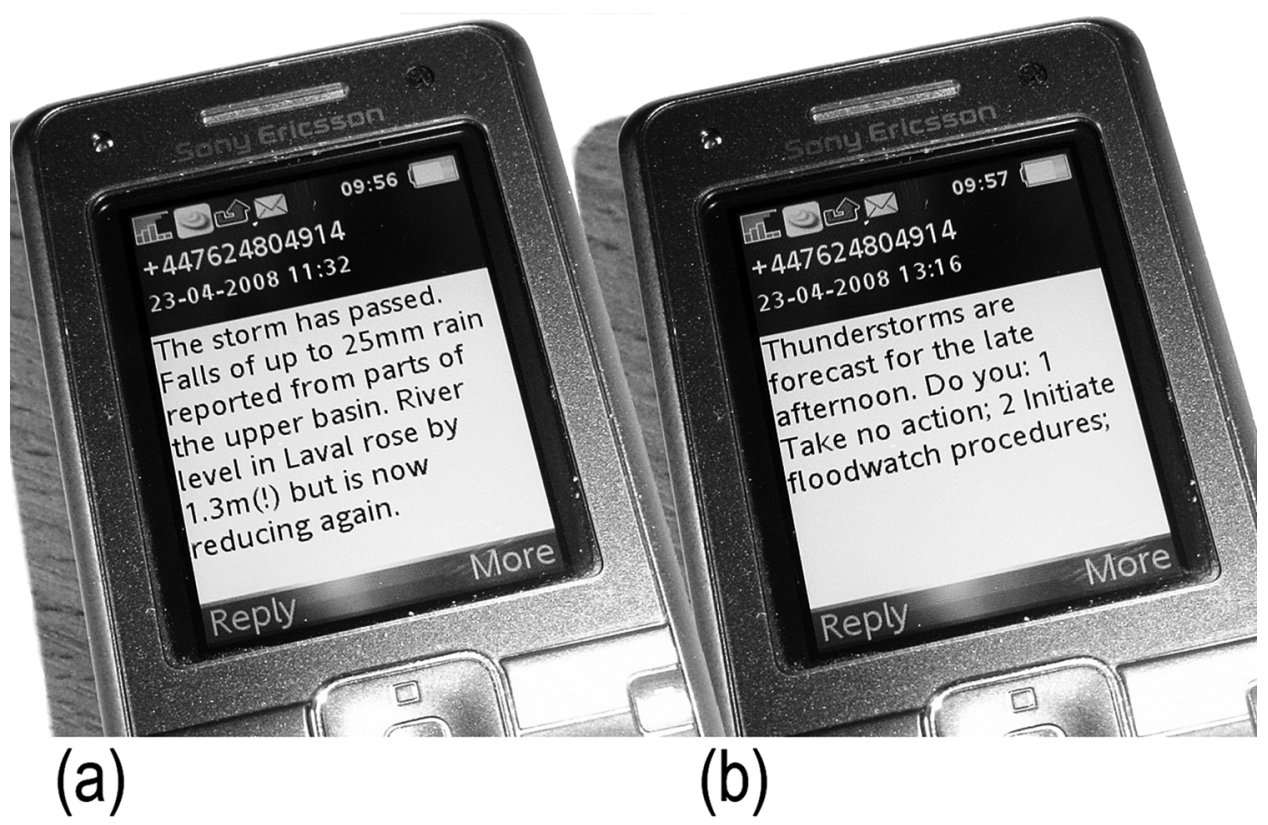

Figure 2. SMS messages used during the flood disaster simulation. (a) Information message; (b) message requiring decision response from student.

The activity encouraged rapid assessment of information and the application of prior theoretical knowledge to a practical context. If learners required further information to support their decision making specific requests had to be made to the tutor, who played the role of a representative from civil defence $H Q$.

\section{The virtual context in the flood disaster simulation}

The virtual physical context for the flood disaster simulation was based on a real geographical location, and although learners were provided with some background on the area, they still had to imagine many of the aspects of the environment. This was particularly important once the simulation was underway and their decisions started to invoke changes in the environment. The virtual social context was in part based on rules and norms established by the tutor and those associated with the role being played, but elements were also created in the learners' imaginations when they considered the effect the flood had on the imaginary residents of the town. Although, in general, questionnaire respondents were neutral about whether the simulation was a realistic experience, they were more likely to disagree with the statement that the activity was artificial and did not reflect what would happen in real life. Some of their criticisms related to elements of the social context - for example, they felt there was insufficient information in some text messages and would have liked the opportunity to select from more than two possible options for action, or even to suggest their own actions. However, evidence from interviewees also suggested that engagement with the physical and social elements of the virtual context was beneficial for their learning:

I think [the simulation] helped to reinforce how these things go through [...] you think it's just common sense sometimes - a flood's going to come, put out some 
sandbags - you don't really think of is it going to cost money, about time, is it going to affect people, what's going to happen downstream. (Female student 1)

It was good to look at a real life situation rather than just a vague sort of thing...you hear the numbers and you hear about floods and things but it doesn't really mean anything. Whereas when you are actually having to prevent death by the text message then you have to...you do look at the situation slightly differently. (Female student 2)

The quotations provided above also illustrate that the interviewees demonstrated cognitive engagement and commitment to the scenario: they give an indication of 'taking a different view' of the scenario and the adoption of a wider perspective than might be obtained by other types of activities. There was also evidence of emotional engagement. Although not representative of all learners in the group the interview respondents both highlighted their 'involvement' with the activity, one commenting that it was a good way to get involved in such a scenario, and the other that being involved encouraged them to do more work. Other emotions were evident, for example the tutor noted that some students suffered a 'mild case of trauma' because mixups with messages led to them wiping out most of the population they were supposed to be defending:

They would come here saying 'I just feel frustrated, I thought I'd done my best but I've killed 50 people'. Telling them they could do it all over again and not to worry about it partly reassured them, but I think, for some of them they thought 'Now I've got a second chance to kill 50 people'. (Tutor)

These comments suggest a level of role engagement which the tutor admitted he had not expected. A wide range of emotions were reported by learners in questionnaire responses, both positive (enjoyment, engagement, involvement) and negative (annoyance, frustration), although the negative emotions were mostly prompted by technical issues (including problems with the service providers' network, and some participants returning messages in inappropriate formats) which impacted on preferred decisionmaking strategies and took the progression of the scenario out of the learner's control. Some learners clearly did not engage fully with their roles, making decisions on the basis of 'common sense' or 'instinct' or even following a conviction that 'option 2 was always the right answer'. Differences in the level of engagement with the scenario and the role are perhaps inevitable in any group of learners, but there is evidence that most learners were engaged by the activity (for example 60\% 'strongly agreed' or 'agreed' that they looked forward to messages arriving).

The simulation interrupted learners' day-to-day activities in a variety of physical locations (including at their place of residence and workplace), yet the real time element was viewed positively and appears to have enhanced engagement with the activity. All of the questionnaire respondents 'strongly agreed' or 'agreed' that they 'enjoyed the real time aspect of the simulation' and were happy to receive messages which disrupted their lives outside normal 'working' hours. Only one questionnaire respondent indicated that the activity intruded negatively on other aspects of their life. One respondent commented that "you felt more involved because you didn't know when you were going to get the updates - that was fun," whilst another "liked the way it brought together University and the outside." One interviewee reported that a group had been sitting together waiting for the first message - "we were all like 'I've got a message.' It was exciting." 
The positive attitude to the disruptive nature of the activity may be enhanced by the fact that the simulation was seen as a novel and innovative activity, particularly in terms of the approach to assessment. For assessment purposes students were required to reflect on and justify the decisions they had made during the simulation in diary format. This was widely applauded as 'not just another boring essay'. However, whether this approach would have an enduring positive effect is brought into question by the comments of one of the interview respondents. She cautioned against too much use of mobile phones for learning in general to prevent boredom and a less positive response - 'oh for goodness sake, not another one' - to the disruption involved.

\section{Discussion}

The notion of virtual context is not explicitly accounted for in Wali, Winters, and Oliver's (2008) definition of mobile learning, and not at all in the work of Frohberg, Göth and Schwabe (2009). It may not be important in all mobile learning applications. However, it does appear to have a role to play in the conceptualisation of mobile simulation activities such as those described above. The virtual context may also assist conceptualisation of some participatory simulations where learning is not constrained to take place in a particular physical location. In particular the virtual context helps to highlight the important role and potential of the disruptive nature of intrusive communication channels for learning activities and the power of a textual narrative to stimulate the construction of an imaginary virtual world.

The disruptive power of mobile devices to transport a user away from their current context warrants further investigation. In the flood disaster simulation the real-time and disruptive aspects of the activity appear to have had an impact on enjoyment and engagement. Considering this further within the framework of context crossing (Wali, Winters, and Oliver 2008) or the notion of 'frame-switching' between real and virtual worlds (Bell 2009) may have value. Loewenstein's (1994) 'Gap Theory' of curiosity may also shed light on learners' reactions to unexpected messages which compel them to engage and investigate something in greater depth. Other work on interruption and the blurring of boundaries between contexts includes that from the design of mobile and SMS games and demonstrates the complexity of issues associated with the juggling of interactions and management of disturbances created by SMS messages (e.g. Tolmie et al. 2008).

The issue of presence also deserves further exploration in connection with teaching and learning. Baños et al. (2005, 90) note that "many authors assume that a person feels present in an environment when his/her cognitive processes lead to a mental representation of a space" and in a study of participants in imagined and virtual spaces suggest that imagination is a good procedure to elicit a sense of presence, although some users may have difficulties in maintaining this sense of presence. In particular "it could be difficult for people to suppress for a long time the actual physical environment...in favour of an alternative and cognitive environment" (98), though this may not be such an issue with an interface such as SMS, which is used for normal day-to-day interactions and which was preferred over email options offered to the flood disaster participants. The use of such a familiar interface may reduce the cues for un-reality that hinder the suspension of disbelief found in $3 \mathrm{D}$ virtual worlds. Klopfer (2008) also suggests that creating a sense of presence is difficult, but cites research by others (Salzman et al. 1999 and Winn et al. 2002), which suggests that increasing presence is associated with increased learning in virtual 
learning environments. Such issues warrant further research in connection with the use of SMS for learning during simulation activities. For example, work to investigate learners' ability to develop and maintain a sense of place and presence using text prompts alone would be interesting.

Other SMS simulations drawing on the model used for the flood disaster simulation are under development and in testing. In particular a contrasting scenario, developing an appropriate mentoring relationship with learners on an adult literacy qualification, is providing further insight into the virtual context and associated issues. In this example the virtual context is completely imaginary. There are no physical features about which information can be provided, and the characteristics of the mentee must be imagined by the mentor. This reflects the real world situation in which a new relationship must be developed with someone one has never met. The social context is informed by the mentor's own professional norms and expectations, and personal preferences, although there are some restrictions imposed by the simulation design on the time limits and nature of responses. There is the potential for this simulation to be more disruptive to learners than the flood disaster example, since participants are all working professionals with other demands on their time and attention. This simulation and others at the early stages of design in the areas of medicine and education will permit further exploration of issues of context, cognitive engagement, persistence and disruption.

There may be other areas relevant to teaching and learning where the development of a more robust virtual context may be beneficial for learners. For example, activities involving the use of SMS in language learning such as vocabulary practice, may benefit from the design of virtual context (e.g. school or hospital) to which vocabulary is relevant and within which practice can take place. Disruptive return to this virtual context may encourage microlearning through repetition and reinforcement. Similarly the use of a virtual context in connection with stories or other narratives may help to engage learners in other situations and disciplines.

\section{Conclusions}

The work on which the concept of the virtual context has been developed is necessarily limited in scope and duration. However, the notion of virtual context allows mobile learning to be de-coupled from the restrictions of the physical context, at least in the case of simulations using SMS, such as the flood disaster management example presented here, and is providing a useful framework for the development of new SMS based simulations in other authentic decision making scenarios. The challenge for designers is to provide a virtual context which is realistic and persistent (physically and socially) within which the learner can play an authentic and engaging role.

The relevance of the virtual context to other mobile learning applications requires further investigation, as there appear to be pedagogical and other benefits of using a virtual context to engage learners. In particular the pedagogic benefits of stimulating learners' imagination so that they construct their own learning spaces to help engagement with learning activities could be beneficial to the development of mobile learning. Consideration of the virtual context may have a role in encouraging deeper reflection and knowledge application, analysis, synthesis and evaluation that will meet the demand from Frohberg, Göth, and Schwabe (2009) for mobile learning applications with 'higher pedagogic ambition'. 


\section{Acknowledgements}

The original concept for the flood disaster simulation was developed at the University of Aberdeen by Alastair Gemmell (School of Geosciences) and Phil Marston with programming done by Ian Finlayson (Directorate of Information Technology). Chris Aldred (School of Education) has designed the mentoring case study scenario. Thanks are also due to Steve Sidaway at txttools.co.uk for assistance with technical aspects of the messaging system used, and to questionnaire and interview respondents.

\section{References}

Baños, R.M., C. Botella, B. Guerrero, V. Liano, M. Alcaniz, and B. Rey. 2005. The third pole of the sense of presence: Comparing virtual and imagery spaces. PsychNology Journal 3, no. 1: $90-100$.

Bell, D. 2009. Learning from second life. British Journal of Educational Technology 4, no. 3: 515-25.

British Broadcasting Corporation (BBC). 2008. Surgeon saves boy's life by text. BBC News. http://news.bbc.co.uk/1/hi/health/7761994.stm.

Cavus, N., and D. Ibrahim. 2009. m-Learning: An experiment in using SMS to support learning new English language words. British Journal of Educational Technology 40, no. 1: 78-91.

Colella, V. 2000. Participatory simulations: Building collaborative understanding through immersive dynamic modelling. Journal of the Learning Sciences 9, no. 4: 471-500.

Cornelius, S., A. Gemmell, and P. Marston. 2008. Real-time simulation on the move: The learner context. Paper presented at Online Educa 08, 14th International Conference on Technology Supported Leaning and Training, December 3-5, in Berlin, Germany.

Cornelius, S., D. Medyckyj-Scott, D. Forrest, A. Williams, and W. Mackaness. 2008. The virtual placement - an alternative to the traditional work placement in the geographical sciences? Journal of Geography in Higher Education 32, no. 2: 287-302.

DuVall, J.B., M.R. Powell, E. Hodge, and M. Ellis. 2007. Text messaging to improve social presence in online learning. Educause Quarterly 30, no. 3: 24-8.

Facer, K., R. Joiner, D. Stanton, J. Reid, R. Hull, and D. Kirk. 2004. Savannah: Mobile gaming and learning? Journal of Computer Assisted Learning 20, no. 6: 399-409.

Frohberg, D., C. Göth, and G. Schwabe. 2009. Mobile learning projects - a critical analysis of the state of the art. Journal of Computer Assisted Learning 25, no. 4: 307-31.

Geddes, S.J. 2004. Mobile learning in the $21^{\text {st }}$ century: Benefit to learners. The Knowledge Tree, Edition 6. Australian Flexible Learning Network. http://knowledgetree.flexiblelearning.net.au/edition06/download/geddes.pdf.

Gemmell. A., I. Finlayson, and P. Marston. In press. First steps towards an interactive realtime hazard management simulation. Journal of Geography in Higher Education.

Hansen, F., and N. Bouvin. 2009. Mobile learning in context - context aware hypermedia in the wild. International Journal of Interactive Mobile Technologies 3, no. 1: 6-21.

Jackson, S., and I. Livingston. 1982. The Warlock of Firetop Mountain. London: Puffin Books.

Kinsella, S. 2009. Many to one: Using the mobile phone to interact with large classes. British Journal of Educational Technology 40, no. 5: 956-8.

Klopfer, E. 2008. Augmented learning: Research and design of mobile educational games. Cambridge, MA: MIT Press.

Kukulska-Hulme, A., and L. Shield. 2008. An overview of mobile assisted language learning: From content delivery to supported collaboration and interaction. ReCALL 20, no. 3 : 271-89.

Kurti, A., D. Spikol, and M. Milrad. 2008. Bridging outdoors and indoors educational activities in schools with the support of mobile and positioning technologies. International Journal of Mobile Learning and Organisations 2, no. 2: 166-86.

Latimer, D. 2008. Text messaging as emergency communication superstar? Nt so gr8. Educause Review 43, no. 3: 84-5.

Laurillard, D. 2002. Rethinking university teaching: A conversational framework for the effective use of learning technologies. 2nd ed. Routledge-Falmer: London.

Loewenstein, G. 1994. The psychology of curiosity: A review and reinterpretation. Psychological Bulletin 16, no. 1: 75-98. 
Margaryan, A., D. Nicol, A. Littlejohn, and K. Trinder. 2008. Students' use of technologies to support formal and informal learning. In Proceedings of world conference on educational multimedia, hypermedia and telecommunications, 4257-66. Chesapeake, VA: AACE. http://www.editlib.org/p/28976.

Naismith, L., P. Lonsdale, G. Vavoula, and M. Sharples. 2004. Literature review in mobile technologies and learning. Report 11: Future Lab Series. http://www.futurelab.org.uk/ resources/documents/lit_reviews/Mobile_Review.pdf.

Ogino, T., M. Suzuki, F. Kusunoki, and I. Hatono. 2008. Cellular phone with GPS based learning support system for field studies. In Proceedings of world conference on educational multimedia, hypermedia and telecommunications, 1812-7. Chesapeake, VA: AACE. http://www.editlib.org/p/28620.

Patten, B., I. Arnedillo Sánchez, and B. Tangney. 2006. Designing collaborative, constructionist and contextual applications for handheld devices. Computers \& Education 46, no. 3: 294-308.

Rettie, R.M. 2005. Presence and embodiment in mobile phone communication. PsychNology Journal 3, no. 1: 16-34.

Salzman, M.C., C. Dede, R.B. Loftin, and J. Chen. 1999. A model for understanding how virtual reality aids complex conceptual learning. Presence: Teleoperators and Virtual Environments, 8, no. 3: 293-316.

Sharples, M. 2005. Learning as conversation: Transforming education in the mobile age, In Proceedings of conference on seeing, understanding, learning in the mobile age, 147-52. Budapest, Hungary. http://www.eee.bham.ac.uk/sharplem/Papers/Theory\%20of \%20learning\%20Budapest.pdf.

Sharples, M., J. Taylor, and G. Vavoula. 2005. Towards a theory of mobile learning. In Proceedings of MLearn 2005 conference, ed. H. van der Merwe and T. Brown. Cape Town: South Africa. http://www.mlearn.org.za/CD/papers/Sharples-\%20Theory\%20of\% 20Mobile.pdf.

Sharples, M., J. Taylor, and F. Vavoula. 2007. A theory of learning for the mobile age. In The SAGE handbook of e-learning research, ed. R. Andrews and C. Haythornthwaite, 221-47. London: Sage.

Squire, K., and E. Klopfer. 2007. Augmented reality simulations on handheld computers. Journal of the Learning Sciences 16, no. 3: 371-413.

Tolmie, P., A. Crabtree, T. Rodden, and S. Benford. 2008. "Are you watching this film or what?" Interruption and the juggling of cohorts. In Proceedings of the ACM 2008 conference on computer supported cooperative work, 257-66. New York: ACM. http:// doi.acm.org/10.1145/1460563.1460605.

Wali, E., N. Winters, and M. Oliver. 2008. Maintaining, changing and crossing contexts: An activity theoretic reinterpretation of mobile learning. ALT-J, Research in Learning Technology 16, no. 1: 41-57.

Wang, M., R. Shen, D. Novak, and X. Pan. 2009. The impact of mobile learning on students' learning behaviours and performance: Report from a large blended classroom. British Journal of Educational Technology 40, no. 4: 673-95.

Winn, W., M. Windschitl, R. Furland, and Y. Lee. 2002. When does immersion in a virtual environment help students construct understanding? In Proceedings of the International Conference of the Learning Sciences ICLS 2002, ed. P. Bell and R. Stevens. Mahwah, NJ: Erlbaum.

Winters, N. 2006. What is mobile learning? In Big issues in mobile learning. Report of a workshop of the Kaleidoscope Network of Excellence Mobile Learning Initiative, ed. M. Sharples, 7-11. Nottingham: Learning Sciences Research Institute, University of Nottingham. http://www.lsri.nottingham.ac.uk/Publications_PDFs/BIG_ISSUES_ REPORT_PUBLISHED. pdf.

Yang, S.J.H. 2006. Context aware ubiquitous learning environments for peer-to-peer collaborative learning. Educational Technology and Society 9, no. 1: 188-201. 